\title{
Chickpea Breeding and Crop Improvement in Ethiopia: Past, Present and the Future
}

\author{
Asnake Fikre $^{1, *}$, Dagnachew Bekele ${ }^{2}$ \\ ${ }^{1}$ International Crops Research Institute for the Semi-Arid-Tropics, India \\ ${ }^{2}$ Ethiopian Institute of Agricultural Research, Ethiopia
}

Received October 16, 2019; Revised November 28, 2019; Accepted December 4, 2019

Copyright $\odot 2020$ by authors, all rights reserved. Authors agree that this article remains permanently open access under the terms of the Creative Commons Attribution License 4.0 International License

\begin{abstract}
This review paper reflects the retrospective and prospective of chickpea breeding in Ethiopia in time course of the last five decades. The full-fledged chickpea breeding in Ethiopia started in the 1970s, by just collection, characterization and evaluation among hundreds of local desi accessions for the key yield limiting challenges of the crop production. Among key challenges include soil wilt-root rot complex, inherent low productivity of accessions, ascochyta blight, pod borer, storage pest, terminal drought, and shriveled seed size. Nonetheless efforts combining the multiple objectives and disciples, and partners together have shade in the enhancement of more than tens of thousands of germplasms flows, inter and intra-accession breeding, vital trait of interest transfer between or among candidate lines. Marker assisted breeding and interspecific hybridization with Cicer spp ( $C$. reticulatum and $C$. echinospermum) are being employed as tools in trait of interest introgression and/or germplasm pool enrichment for immediate future use. The breeding technical efficiency have also been in progress in handling complex of derived population to enhance probability of progressive genetic gain explained through super variety development from germplasm lines, that changed chickpea production and productivity landscape. Ethiopian chickpea has enjoyed by the Kabuli types joined since mid-1980s and accelerates over the desi types due to some peculiar traits (AB-resistance, taste, seed texture etc) liked by the market and consumers. Hence, in its age of breeding, 23 super performing varieties released in both types, yield have been quadrupled from $700 \mathrm{~kg} / \mathrm{ha}$, seed size tripled from $11 \mathrm{~g} / 100$ seed, market volume and values improved significantly, income per unit area has more than tripled, area expansion almost doubled.
\end{abstract}

Keywords Chickpea Breeding, Crop Improvement

\section{Introduction}

Legumes are important sources of protein in the diets of millions of people in the world [1]. Among the different legumes, chickpea (Cicer arietinum L.) is categorized in Fabaceae (Leguminosae) family, one of the oldest and most widely consumed legumes in the world and it is a staple food crop particularly in tropical and subtropical areas. Ethiopia is one of the major producers of chickpea and ranked sixth worldwide in 2016 and serves as a multi-purpose crop (FAO, 2006). In Ethiopia, the use of chickpea grains for human food has long history and used in different forms as green vegetable (green immature seed), 'Kolo' (soaked and roasted), 'nifro' (boiled seeds) and 'wot' (sauces) made up of 'shiro' (powdered seeds) or blended with cereals and/or legumes for preparing of infant and young children foods using traditional food processing techniques like soaking, germination, fermentation, boiling, roasting etc.

Research advances in chickpea breeding, crop management practices over the last four decades resulted in the development and release of technologies that brought a significant change in the productivity, adaptability and production; thereby improving the livelihood of the small farmers.

Commercialization of chickpea through appropriate technology adaptation supported by effective seed system has proved plausible formulation of change. Changes in productivity, production, income generation and scale are happening in a steady progress after being stimulated by subsequent generation of Tropical Legumes (TL) projects. TL project was instrumental in deploying varieties that have been hardly penetrating new horizon of socio-economic change like Shasho, Arerti, Habru, Natoli varieties. Multiple factors among, multiple stakeholder's attributes, technology appropriation, adaptation, crop management have all been operated more of in a synergy than less of any antagonistic.

Production volume of chickpea has shown steady 
improvement over the last decade with currently reaching close to 0.5 million tons per annum. The major contributor of this production is the dramatic productivity improvement per unit area of the crop than area expansion. The productivity level currently $2058 \mathrm{~kg} / \mathrm{ha}$ is among the highest records in the world and is double to the global average. The key progressive factors of success in Ethiopian chickpea is linked with the time taking attempt of any improvement in trait of interests (Asnake, 2016c).

The constraints in chickpea have also been made some evolvement in time, biotic challenges like of sclerotic virus attacks, market preference for kabuli bold seeded produces, seed quality issues are relatively newly arriving issues. Thus, a continuous and conscious genetic improvement along with management practices is assumed to take part as time advances.

\section{Significance of Chickpea in Ethiopian Crop Production System}

The 242, 703 ha (CSA, 2017) area coverage of the crop is spatially intermingled and covers over $75 \%$ of the main annual cropping land area of the country. This means the cropping system of cereal based agriculture is shared by chickpea cropping in rotational cropping, double cropping or intercropping. In that case it attributes for the sustainable intensification of the field crop production including tef, wheat, sorghum, barley, millet, rice to mention some. Tsedalu et al (2018) has reported from double cropping of wheat and chickpea per a single season would prevail rewards to a maximum of 1.99 , implying the yield and benefit maximization per unit area per season. The marginal rate of return was $104 \%$. The highest grain yield in the double cropping system was obtained with Dinknesh wheat variety $(2709 \mathrm{~kg} / \mathrm{ha})$ double cropped with Natoli chickpea variety ( $2562 \mathrm{Kg} / \mathrm{ha}$ ) and this combination.

Chickpea is one of the top competitive enterprise both for local and export marketing, among different categories of crops viz., coffee, oil crops, cereals, legumes, vegetables, fruits, stimulants, fiber crops of some 100 commercialized species in the country. Hence, market is one key deriver of the chickpea in the country. Yield of chickpea has surpassed $3 \mathrm{t} / \mathrm{ha}$ and generated an associated income of 4800-6000 USD/ha at pick local price, which is three-fold income gain compared to the price in the in 2000s (ICRISAT Newsletter 2018).

Evidences showed that chickpea can save a third of the nitrogen source fertilizers need for the subsequent rotational cereals.

\section{Chickpea Breeding Methods in Ethiopia}

In the early phases of chickpea breeding, selections from local landraces were used to develop varieties. Later the national chickpea improvement program created significant genetic variabilities for major agro-morphological traits desired by the breeding program through the introduction of diverse germplasm lines from different sources. The major agro-morphological traits prioritized by the breeding program includes productivity, seed size, plant phenology and type, and resistance to key biotic and abiotic stresses prevalent in the country; particularly resistance to wilt/root rot diseases complex, ascochyta blight, major insect pests, drought, moisture and heat stresses.

Introduction was mainly facilitated through obtaining generic resources and advanced germplasm lines from international institutes/organizations particularly from ICRISAT and ICARDA, and exchange of material with fellow breeders and breeding programs. In Ethiopia, most of the released varieties were developed through rigorous evaluation and critical selection of introduced germplasm lines (Table 1) for diverse agro morphological traits over years under diverse agro-ecologies in multiple environments/locations. Most of these introduced germplasm lines have been developed through hybridization.

The main objective of hybridization was to combine desirable traits from two or more parents into a single cultivar. Single, three way or multiple crosses were used in the breeding program to generate diverse germplasm lines for different agro morphological traits. When the objective of creation of genetic variability is to replace the existing variety with a superior one, the existing variety with good adaptation to the local environment was used as one of the crossing parent and the other parent was chosen to complements the first parent. Single crosses were mainly employed to transfer resistance against biotic and abiotic stresses such as wilt, ascochyta blight, larger seed size and etc.

Besides, to create genetic variability in diverse desirable agro morphological traits, multiple crosses were performed using divergent parental lines. The progenies of three-way crosses were more variable with wide genetic base than single crosses, and varieties developed from multiple crosses had wider adaptation for a range of environments. In chickpea two crossing techniques; pollination after emasculation and pollination without emasculation have been reported, and success of crossing with emasculation varied from 5 to $17 \%$; while the success rate varied from 20 to $50 \%$ by pollination without emasculation (Shweta and Million, 2017) . In Ethiopia pollination after emasculation is commonly practiced and the success rate can be increased by selecting large lateral flower buds than the terminal buds, avoiding mechanical injury to the floral parts at the time of emasculation and pollination. Under low temperature emasculation is done in the afternoon and pollination in the next morning. In case of high temperature emasculation followed by immediate pollination is recommended. Backcross breeding was also used to incorporate one or few traits from different genetic background into a well-adapted variety. 
Table 1. Breeding methods and chickpea varieties released in Ethiopia for commercial production from 1974 to 2019

\begin{tabular}{|c|c|c|c|c|}
\hline Variety & Type & Origin & Breeding methods & Year of release \\
\hline DZ-10-4 & Kabuli & Ethiopia & Local selection & 1974 \\
\hline DZ-10-11 & Desi & Ethiopia & Local selection & 1974 \\
\hline Dubie & Desi & Ethiopia & Local selection & 1978 \\
\hline Mariye & Desi & ICRISAT & Introduction \& Hybridization* & 1985 \\
\hline Worku & Desi & ICRISAT & Introduction \& selection & 1994 \\
\hline Akaki & Desi & ICRISAT & Introduction \& selection & 1995 \\
\hline Arerti & Kabuli & ICARDA & Introduction \& Hybridization & 1999 \\
\hline Shasho & Kabuli & ICARDA & Introduction \& Hybridization & 1999 \\
\hline Habru & Kabuli & ICARDA & Introduction \& Hybridization & 2004 \\
\hline Chefe & Kabuli & ICARDA & Introduction \& Hybridization & 2004 \\
\hline Ejere & Kabuli & ICARDA & Introduction \& Hybridization & 2005 \\
\hline Teji & Kabuli & ICARDA & Introduction \& Hybridization & 2005 \\
\hline Kutaye & Desi & ICRISAT & Introduction \& Hybridization & 2005 \\
\hline Mastewal & Desi & ICRISAT & Introduction \& Hybridization & 2006 \\
\hline Fetenech & Desi & ICRISAT & Introduction \& Hybridization & 2006 \\
\hline Yelbie & Kabuli & ICRISAT & Introduction \& Hybridization & 2006 \\
\hline Natoli & Desi & ICRISAT & Introduction \& Hybridization & 2007 \\
\hline Acos Dubie & Kabuli & Mexico & Introduction \& adaptation & 2009 \\
\hline Minjar & Desi & ICRISAT & Introduction \& Hybridization & 2010 \\
\hline Kasech & Kabuli & ICRISAT & Introduction \& Hybridization & 2011 \\
\hline Akuri & Kabuli & ICRISAT & Introduction \& Hybridization & 2011 \\
\hline Kobo & Kabuli & ICRISAT & Introduction \& Hybridization & 2012 \\
\hline Dalota & Desi & ICRISAT & Introduction \& Hybridization & 2013 \\
\hline Teketay & Desi & ICRISAT & Introduction \& Hybridization & 2013 \\
\hline Dimtu & Desi & ICRISAT & Introduction \& Hybridization & 2016 \\
\hline Hora & Kabuli & ICARDA & Introduction \& Hybridization & 2016 \\
\hline Dhera & Kabuli & ICARDA & Introduction \& Hybridization & 2016 \\
\hline Koka & Kabuli & ICRISAT & Introduction \& Hybridization & 2019 \\
\hline Geletu & Desi & ICRISAT & Introduction \& MABC* & 2019 \\
\hline
\end{tabular}

*Crossing for hybridization and MABC(Marker Assisted Back Cross) performed at the origin before introduction

In the breeding program, a combination of bulk and pedigree methods are mainly used in handling several segregation generation developed from different crossing schemes. In early segregating generations, selection is done for simple traits such as disease resistance and seed traits. Screening several segregation populations and local germplasm accessions for resistance/tolerance to Fusarium wilt using an aggressive wilt sick plots at Debre Zeit Agricultural Research Center allows the identification of sources of resistance for the disease. Moreover, the existence of different hot spot testing sites for aschochyta blight, drought, moisture and heat stresses allows the breeding program to screen and evaluate several hundred advanced germplasm lines over years and over locations to identify best performing genotype for formal trial and official variety release. Single plant selection for yield mainly starts in $F_{4}$ or $F_{5}$ generation. Due to high environmental effects, selection for complex quantitative traits such as drought and heat stresses usually performed in later stages. 


\section{Trends in Genetic Improvement and Crop Yield Potential}

Obviously genetic recombination of diverse parental sources has been demonstrated with improved hybrids in chickpea. The Ethiopian chickpea breeding and improvement program since its inception in 1970s, has passed through progressive of stepladders both technical and delivered-wise. Taken part right after collection expeditions and characterization of accessions for trait of interests. Some 15, 000 germlines (Asnake, 2016c) of chickpea have been used in the improvement program including recombinant lines and/or accessions, out of which some 25 varieties $(0.17 \%)$ have been released for commercial production.

1970s-1980s: Prior to the mid-1950s there was no agricultural research in Ethiopia, except by a few plant explorers, chiefly from Europe, who mainly reported the wealth of genetic resources in most of the economic plants. After Ethiopia started seeking the aid of the western world to modernize its agriculture, one of the top priority programs focused on the opening of agricultural schools and colleges. Although different research programs started in the early 1960s, coordinated food legume research did not materialize prior to 1972 (Asfaw et al, 1994). The inception of chickpea breeding program has embarked on understanding the challenges of chickpea production and looking for genetic improvement basis to curb some of those key gaps. Accordingly, this was the period where local collection of 859 accessions (Dawit et al 1994) has been collected nationally and put under station observation and characterization. Diversity index was computed to see diversity levels among collections for the specific key challenges, including low productivity, susceptibility to biotic threats Fusarium, ball worm, shriveled seed size, drought, water logging, adaptability. Among these local landraces, DZ-10-1 (kabuli), DZ-10-2 (desi), DZ-10-4 (kabuli), DZ-10-11 and Dubie (desi) and Marye were selected, multiplied and distributed to the farmers in the Yerer, Kereyu and Menagesha awrajas in the period. Except Marye (K-850-3/27 x F378) which was from ICRISAT source, all others were releases of the Ethiopian collections(Table 1). Hence, the breeding period that derived the first-generation cultivars was described by promotion of the accession germlines dominantly attributed by the country; and desi were the dominant chickpea type.

1990s: This period is typically putting a new milstone in the breeding program, that is the integration of kabuli type chickpea improvement by deploying germplasm resources from CG centers. In this period ground breaking aschochyta blight resistant kabuli varieties; Arerti (FLIP-89-84C) and Shasho (ICCV 93512) were released. These varieties are still competitive in production. Along with these two desi varieties have been also released. This period is also the time where a new shift from accession based to germplasm based breeding took part; and ICRISAT and ICARDA were typical centers in the partnership of breeding materials transfer.

2000s: This decade is productive breeding period as some half of the total varieties is released in the period. Dozens of germplasm lines have been flowing to the national program under different trait of interests (drought, ascochyta blight, yield, seed size, maturity groups, wilt resistance etc). The national program has also made progress on crossing and progenies development; and multilateral projects like tropical legume project, and other technology promotion projects have been in the play. This is also progressive period for breeding to start marker-based breeding (MAB, MABC) using drought traits. Digital scoring was started. This period was also the time for chickpea development impact hit the apex and the seed system was stimulated.

2010s: The current period has also signified by progressive investment in the chickpea breeding and developing breeding techniques. Genetic gain, being central metrics for progress, different effectiveness and efficiency approaches were employed. Introgressive breeding (C. arietinum vs C.echinospermum/C.reticulatum), multiple crossing probability approach, electronic data capture in breeding data management system, quality oriented breeding, shortening the breeding cycle, gene pyramiding/MAGIC/ plat forms are on integration.

Dagnachew et al (2014) computed genetic progress in chickpea and estimate from the slope of the graph of linear regression, the absolute genetic progress in grain yield for desi varieties was $\sim 32 \mathrm{~kg} \mathrm{ha}^{-1}$ year- $1\left(\mathrm{P} \leq 0.001, \mathrm{R}^{2}=0.725\right)$ with relative genetic progress of $2.13 \%$ year $^{-1}$ (Figure 1 ). Conversely, there was insignificant $\left(15.3 \mathrm{~kg} \mathrm{ha}^{-1} \mathrm{year}^{-1}\right)$ $\left(\mathrm{R}^{2}=0.164\right)$ genetic progress for kabuli types chickpea with respect to grain yield with relative genetic progress of $0.87 \%$ year ${ }^{-1}$. The absolute genetic progress in terms of 100 seed weight were $0.320 \mathrm{~g}_{\text {year }}{ }^{-1}\left(\mathrm{R}^{2}=0.626\right)$ for desi, and $0.931 \mathrm{~g}$ year $^{-1}\left(P \leq 0.001, R^{2}=0.764\right)$ for kabuli with relative genetic progress of $2.58 \%$ and $8.62 \%$ year $^{-1}$, respectively. 

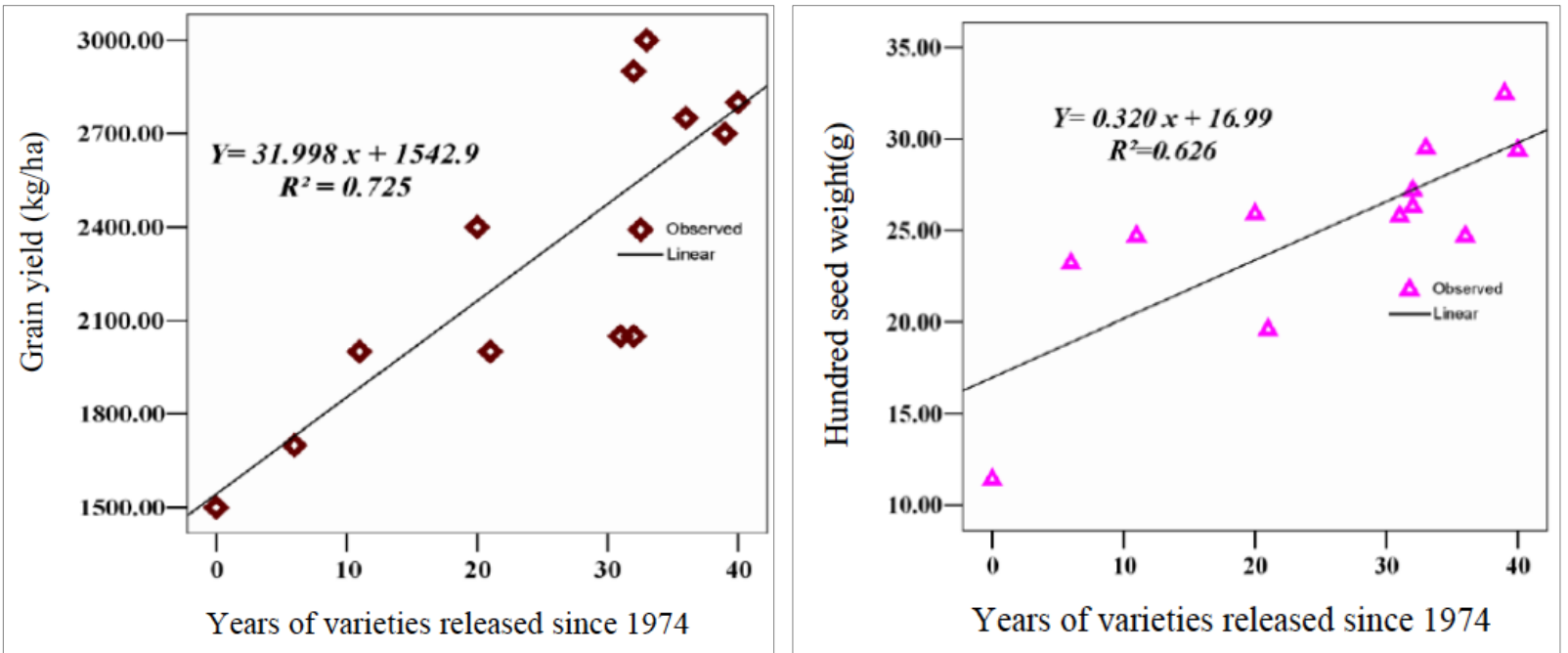

Figure 1. Genetic progress in grain yield and hundred seed weight for desi type chickpea

Besides, the rates in variety release, yield gain and the yield potential of Ethiopian chickpea has been portrayed below (Figure. 2). The rates kept Ethiopia one of the productivity center in the world.

\section{Yield gain $=60.4 \mathrm{~kg} / \mathrm{ha} / \mathrm{yr}$}

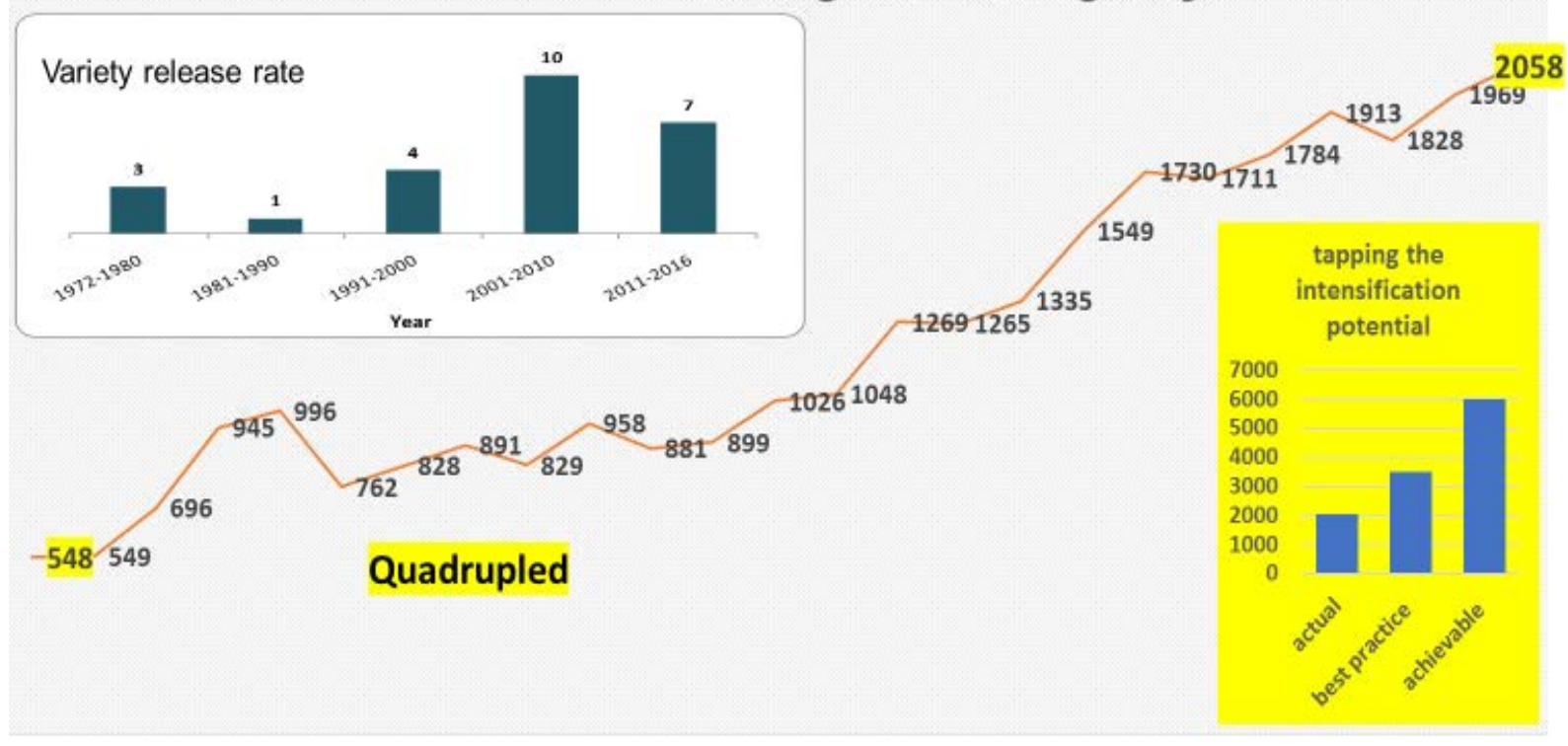

1993199419951996199719981999200020012002200320042005200620072008200920102011201220132014201520162017

Figure 2. The rates of variety release, yield gain and the yield potential of chickpea in Ethiopian 


\section{Studies in Traits of Interests}

Thus far producers put productivity, resistance, adaptation traits as first level priority, and to be followed by market and taste. Agro processing industries, mushrooming now in the country, are looking for appropriate varieties both for processing and nutritional content like protein and amino acid profile. Asnake (2016b) has summarized trait of interests in Ethiopian legumes and reported some commonalities.

\section{Chickpea Agroecological Adaptation and Production System Management}

One of the long breeding objectives in chickpea has been looking for wider adaptation in the underlying diverse agroecological settings Ethiopia is endowed with. To this effect thousands of germplasm materials have been evaluated across locations to calculate stability and superiority for key traits. Those earlier released varieties have been resulted from such approach. However, the diverse agroecologies have got diverse biotic and abiotic constraints to produce the crop. To this effect humid agroecologies favors foliar fungal diseases like Ascochyta blight (Ascochyta rabiei), the vertic-clay soil of the central highlands poses soil related diseases like fusarium wilt (Fusarium oxysporum f.sp. ciceris), dry root rot (Rhizoctonia bataticola), soft rot (R. solani), collar rot (Sclerotium rolfsii) (Niguse et al, in press). At the same time lowland areas expose the crop commonly to drought and heat. Sufficient genetic diversity was prevailed when target germplasms were evaluated under heat zone in Ethiopia (Tesfashbamlak et al., 2018).

Crop management using double cropping system was assessed as a significant enhancer of yield gain (Tsedalu et al, 2018) wand was dependent on variety by management interaction. Better yield was assured using population management and was reported that 50 plants $/ \mathrm{m}^{2}$ has a $30 \%$ yield advantage over the established 33plants $/ \mathrm{m}^{2}$ density (Shiferaw et al, 2014); and the irrigation water requirement were established under variety by management interaction.

Chickpea has shown sporadic and conditioned responses for fertilization input. Hence, there is no single recommendation of $\mathrm{P}$ or $\mathrm{N}$ sources based on solid evidences. On the other hand, there has considerable variation among chickpea germlines in response treatments of irrigation (Niguse et al., 2017), seed priming (Abebe et al., 2016), heat (Tesfashbamlak et al., 2018) and location (Getachew et al., 2015; Asefa et al., 2017) in Ethiopia.

\section{Pro and Against Factors in Chickpea Competitiveness}

The breeding program of any crop is driven by the demand side. The demand comes from the consumption, market, processing, production efficiency, adaptation, quality points of views. Thus, the traits to be packed with in a variety are much related to this concept. In this regard those progressive achievements of the program are expressed in terms of sellable traits. Continuous favorable alleles aggregation moved chickpea producers mean crop yield from less a tone/ha to two tones/ha in the last two decades (CSA, 1997-2017) while under best adoption it gave 3.5 tons/ha (Asnake, 2014), seed size form 10s of grams to 60s of gm/100seed (Dagnachew et al., 2016), a complete resistance to the devastating ascochyta blight restoration sufficiently in kabuli gen pools and some in desi types; test preference of green pod consumption of Marye variety ( Yidnekachew and Asnake, draft manuscript to be submitted), mechanization responsive plant architype development and release (DZ-2012 CK-009/FLIP 0163), preference in nutrition and food engineering quality (Ebsa et al, 2018). The crop competitive advantage emanates from multitude of agronomic, farming system, resilience, products, marketing, nutrition and feed value attributions. Thus, technologies that have been generated in time has kept the crop to one of the top priorities in the Agri-system.

Despite all these, chickpea commodity is still facing biotic and abiotic challenges. Among the top constraints include rhizosphere-complex diseases, stunt virus, ball worm, bruchids, heat, poor nutrient density, and cold. The effort in breeding would have the opportunity taping those to-be-enhanced potentials using novel germplasm development scheme, including migrating gens from wild resources; as initiated in the recent project (http://chickpealab.ucdavis.edu/).

\section{Catching Breeding and Traits of the Future}

The demand for chickpea has remained high and quality driven. The attributions of quality produce are combinations of genetics $\mathrm{x}$ environment $\mathrm{x}$ management. Still gaps in bold seeded and high yielding, nutritional dense, resistance to multiple bio-threats, good taste and agro-processeing, resilient to turmoil of agro climatic factors, preferred seed color and texture, emerging unprecedented issues are some of the top focus areas in chickpea improvement program. The breeding program needs to respond to such advanced demands following innovative and cutting-edge technologies as tool to facilitate gains. Predicted breeding should also be part of the program to respond to tomorrows demand and market. The yield potential should be improved if and only if genetic gains are happening in the breeding outputs.

This suggests that in the breeding program, there is an urgent need to integrate contemporary approaches to enhance precision and efficiency of selections in the segregating generations for higher and rapid genetic gains. 
Precision in selection for different biotic and abiotic stresses such as disease resistance, drought and heat tolerance can be greatly improved by screening several advanced germplasm line/segregating generation under controlled environmental conditions or at hot spot locations.

Genomics assisted breeding (GAB) techniques, particularly marker assisted backcross breeding, marker assisted selection/marker assisted recurrent selection have a great potential to enhance precision and efficiency of chickpea breeding program (Gaur et.al, 2012). These days, several success stories of GAB to develop superior varieties are reported in different pulse and cereal crops (Varshney et al., 2006 and Varshney et al.,2010). Therefore, integration of genomics tools in Ethiopia chickpea breeding program has a great potential to speed up the efficiency of selections in the segregating generations for higher and rapid genetic gains.

Moreover, single seed descent and speed breeding/rapid generation advancement methods are already in use at present and needs to be further strengthen to reduce the time required to reach the desired level of homozygosity and to speed up the release of appropriate varieties with desired traits. Adoption of speed breeding technology by generating 4-6 generations per year will be contributing to accelerate genetic gain in legumes breeding program (Varshney et al., 2019).

\section{REFERENCES}

[1] Abebe Sori , R P S Tomer, Asnake Fikre. 2016. Effect of Hydro- and osmo- priming on seed quality of chickpea (Cicer arietinum L.). In Lijalem Korbu, Tebikew Damite and Asnake Fikre (eds). Harnessing Chickpea Value Chain for Nutrition Security and Commercialization of Small hoder Agriculture in Africa. Jan 30-2 Feb, Debere Zeit, Ethiopia.

[2] Asfaw Telaye, Geletu Bejiga, Saxena, Mohan C. and Solh, Mahmoud B. (eds.) 1994. Cool-season Food Legumes of Ethiopia. Proceedings of the First National Cool-season Food Legumes Review Conference, 16-20 December 1993, Addis Abeba, Ethiopia. ICARDA/Institute of Agricultural Research. ICARDA: Aleppo, Syria, vii + 440 pp.

[3] Asnake F. Woldemedhin. 2016c. Progresses of chickpea research and development in Ethiopia. In Lijalem Korbu, Tebikew Damite and Asnake Fikre (eds). Harnessing Chickpea Value Chain for Nitrition Security and Commercialization of Smallholder Agriculture in Africa. Jan 30-2 Feb, Debere Zeit, Ethiopia.

[4] Asnake Fikre. 2016b.Unraveling Valuable Traits in Ethiopian Grain Legumes Research Hastens Crop Intensification and Economic Gains: A Review. Universal Journal of Agricultural Research 4(5): 175-182, 2016

[5] Asnake FIKRE.2014. An overview of chickpea improvement research program in Ethiopia. The journal of the International Legume Society. Issue 3, June 2014.

[6] Assefa Funga, Megersa Tadesse, Million Eshete, Asnake Fikre, Lijalem Korbu, Nigussie Girma, Dagnachew Bekele, Ridwan Mohamed, Zewdie Bishaw, Ganga Rao NVPR, Moses Siambi, Emmanuel Monyo, Pooran Gaur, Chris Ojiewo.2017. Genotype by environment interaction on yield stability of desi type chickpea (Cicer arietinum L.) at major chickpea producing areas of Ethiopia. Australian Journal of Crop Sciences: 11(02):212-219.

[7] Central Statistical Authority. [1997-2017]. Agricultural sample survey. Results on area, production and yield of major crops in Ethiopia. Addis Ababa, Ethiopia.

[8] Dagnachew Bekele, Asnake Fikre, Million Eshete, Lijalem Korbu and Nigusie Girma. Genetic progresses achieved in Ethiopian chickpea (Cicer arietinum L.) breeding program based on grain yield and seed size. In Lijalem Korbu, Tebkew Damte and Asnake Fikre (eds). 2016. Harnessing Chickpea Value Chain for Nutrition Security and Commercialization of Small hoder Agriculture in Africa. 30th January - 1st February 2014 Debre Zeit, Ethiopia.

[9] Dawit Taddesse, Asfaw Telaye and Geletu Bejiga. Genetic Resources in Ethiopia. In Asfaw Telaye, Geletu Bejiga, Saxena, Mohan C. and Solh, Mahmoud B. (eds.) 1994. Cool-season Food Legumes of Ethiopia. Proceedings of the First National Cool-season Food Legumes Review Conference, 16-20 December 1993, Addis Abeba, Ethiopia. ICARDA/Institute of Agricultural Research. ICARDA: Aleppo, Syria, vii + 440 pp.

[10] Ebisa Olika Keyata, Solomon Abera, Asnake Fikre. 2018. Effect of Processing Methods on Proximate Composition and Functional Properties of Improved Chickpea (Cicer arietinum L.) Varieties Grown in Ethiopia. Food Science and Quality Management. Vol. 72, 2018.

[11] Food and Agricultural organization statics (FAOSTAT), 2006. Available at: http://faostat.fao.org/site/291/default.as px (accessed 6.03.16).

[12] Getachew Tilahun Firew Mekbib, Asnake Fikre and Million Eshete. 2015. Genotype x environment interaction and stability analysis for yield and yield related traits of Kabuli-type Chickpea (Cicer arietinum L.) in Ethiopia. African Journal of Biotechnology. Vol. 14(18), pp. 1564-1575, 6 May, 2015.

[13] Gaur, P. M., Jukanti, A.K., Varshney, R. K. 2012. Impact of Genomic Technologies on Chickpea Breeding Strategies. Agronomy, 2:199-221; doi: 10.3390. ISSN 2073-4395.

[14] Kalve and Tadege. 2017. A comprehensive technique for artificial hybridization in Chickpea (Cicer arietinum). Plant Methods. 13:52. DOI 10.1186/s13007-017-0202-6.

[15] Negussie Tadesse, Seid Ahmed , Asrat Zewdie, Million Eshete, Asnake Fikre, Gemechu Keneni, Wulita Wondwosen, Beyene Bitew, Asnakech Tekaglign, Berhanu Bekele, Samuel Sahile, Wubshet Alemu, Ermias Teshome, Teklay Abebe, Tolessa Bedassa , Yasin Goa and Ersulo Lirie. Advances in diseases management research in highland food legumes of Ethiopia. Ethiopian Crop Science Society Journal (in press of special edition).

[16] Nigusie Girma, Asnake Fikre \& Chris O. Ojiewo.2017. The Genotypic and Phenotypic Basis of Chickpea (Cicer arietinum L.) Cultivars for Irrigation-Based Production in 
Ethiopia. ISSN: 1835-2707 doi: 10.21475/ajcs.17.11.10.pn e413.

[17] Shiferaw Mebrat, Tamado Tana and Asnake Fikre.2014. Response of Kabuli chickpea (Cicer arietinum L.) varieties to plant spacing at Debre Zeit, central Ethiopia. In Lijalem Korbu and Nigusie Girma. Genetic progresses achieved in Ethiopian chickpea (Cicer arietinum L.) breeding program based on grain yield and seed size. In Lijalem Korbu, Tebkew Damte and Asnake Fikre (eds). 2016. Harnessing Chickpea Value Chain for Nutrition Security and Commercialization of Small hoder Agriculture in Africa. 30th January - 1st February 2014 Debre Zeit, Ethiopia.

[18] Tesfashbamlak Mola, Shimelis Alemayehu, Asnake Fikre, Chris Ojiewo, Ketema Alemu, and Tulu Degefu.2018.Heat Tolerance Responses of Chickpea (Cicer arietinum L.) Genotypes in the Thermal Zone of Ethiopia, a Case of Werer Station. EJCS, volume 6; 95-118.

[19] Tsedalu Jemberu, Asnake Fikre, Yimer Abeje1, Birkie Tebabal1, Yonas Worku1 and Tesfaye Jorgi.2018. Agronomic and Economic Evaluation of Wheat-Chickpea Double Cropping on the Vertisol of Takusa, North Western Ethiopia. EJCS, volume 6; 67-78.

[20] Varshney, R.K., Hoisington, D.A., Tyagi, A.K. 2006. Advances in cereal genomics and applications in crop breeding. Trends Biotechnol, 25: 1.

[21] Varshney, R.K., Pandey, M.K., Bohra, A., Singh, V.K., Thudi, M. 2018. Toward the sequence-based breeding in legumes in the post-genome sequencing era. Theoretical and Applied Genetics. 132: 797-816

[22] Varshney, R.K.,Thudi, M., May, G.D., Jackson, S.A. 2010. Legume Genomics and Breeding. Plant Breed. Rev. 33, 257-304. 